\title{
INVOLVEMENT OF THE PERIPHERAL NEURONS IN DIABETES MELLITUS *
}

\author{
WALTER M. KRAUS, M.D. \\ NEW YORK \\ Introduction \\ Reports of Pathologic Conditions in the Literature \\ Clinical Reports in the Literature \\ (a) Polyneuritis \\ (b) Mononeuritis \\ (c) Motor Type \\ (d) Sensory Type \\ (e) Cranial Palsies \\ Statistics of Personal Observations \\ Explanation of the Site of Involvement \\ Conclusions
}

\section{INTRODUCTION}

The object of this paper is to review critically the state of our knowledge of the site of involvement of the peripheral neurons in diabetes mellitus; to this will be added some data and opinions from my own experience with particular reference to the question of neuritis.

REPORTS OF PATHOLOGIC CONDITIONS IN THE LITERATURE

The pathologic reports are scanty and unsatisfactory. They may be roughly divided into those which place the lesion in the spinal cord and those which place it in the peripheral nerves. The last review is by Schweiger, ${ }^{1}$ who discussed especially changes occurring in the intramedullary sensory roots and posterior columns. Schweiger gathered the case reports of sensory tract and root disease up to 1909.

Because of complicating syphilis and tuberculosis all of these cases, with the exception of two, that of Souques and Marinesco ${ }^{2}$ and Schweiger's second case ${ }^{1}$ must be discarded. There is no case report for the former, and in the latter all that is said as to examination is "patellar reflexes present, sensation of the legs diminished. The patient died in coma." This evidence is not very convincing. Findlay ${ }^{3}$ reported pathologic findings after Schweiger, but his patient was also tuberculous with a positive sputum, therefore his case cannot be accepted, for tuberculosis may also cause posterior column degeneration.

* Read at the Forty-Seventh Annual Meeting of the American Neurological Association, Atlantic City, N. J., June. 1921.

1. Schweiger, Ludwig: Ueber die tabiformen Veränderungen der Hinterstrange beim Diabetes, Arbeiten aus dem Neurologische Institut der Wiener Universität 14:391, 1908.

2. Souques and Marinesco: Lesions de la moelle epinière dans un cas de diabète sucré, Rev. Neurol. 5:654, 1897.

3. Findlay: Changes in the Peripheral Nerves in a Case of Diabetes Mellitus, Glasgow M. J. 1907, p. 256. 
Reports of anterior horn cell degeneration are also found, but none except Marinesco's case in $1901^{4}$ is free from complications. This case therefore yields no reliable evidence of primary peripheral neuritis.

Changes in the peripheral nerves have been reported, but of these cases few are free from such complications as infected gangrene, tuberculosis and syphilis. None is reported after the introduction of the Wassermann test.

Summary.-1. We have no reliable pathologic evidence except the reports of Souques and Marinesco, of Schweiger and of Marinesco. The clinical findings here are too meager to make these reports of value.

2. There is no pathologic evidence of primary peripheral neuritis.

\section{CLINICAL REPORTS IN THE LITERATURE}

The clinical reports are roughly divisible into those describing mononeuritis or polyneuritis, and those describing chronic anterior poliomyelitis. It is noteworthy that, with few exceptions, the findings indicate that the peripheral neurons are affected either in their sensory or motor parts. The cases of so-called mononeuritis are either exclusively sensory or show atrophy or paresis.

(a) Polyneuritis.-In the group of about twenty cases reported as polyneuritis it is remarkable that, with only one exception, the clinical picture is either sensory, objective and subjective, or motor with no objective sensory changes. In both groups pain or neuralgia was present. Buzzard's ${ }^{5}$ case alone showed involvement of both sensory and motor fibers. With this exception the reported cases suggest disease either of the motor cells and roots or of the sensory roots. They do not indicate involvement beyond the junction of the motor and sensory roots, that is, peripheral neuritis.

The cases of Pitres and Marchand (1917) ${ }^{6}$ Reich, ${ }^{7}$ Nonne ${ }^{8}$ and $\mathrm{Charcot}^{9}$ showed motor involvement, the only sensory disorder being

4. Marinesco, G.: A Case of Diabetic Paraplegia. Read at a meeting of the Neurological Society of Paris, July 4, 1901; Abstr., Neurol. Centralbl., 1901, p. 94.

5. Buzzard: Illustrations of Some Less Known Forms of Peripheral Neuritis, Especially Alcoholic Monoplegia and Diabetic Neuritis, Brit. M. J., 1890 , p. 1422.

6. Pitres and Marchand: Des polynevrites diabétiques, Progres méd. 36: 295-297 (Sept. 8) 1917; abstr., J. A. M. A. 69:1834 (Nov. 24) 1917; abstr., Rev. Neurol. 23:141, 1918.

7. Reich, A.: A Case of Diabetic Multiple Peripheral Neuritis, Med. Rec. 45: 59 (Jan. 13) 1894.

8. Nonne: Ueber Poliomyelitis bei Diabetes Mellitus, Berl. klin. Wchnschr. 1896, No. 10, March 9.

9. Charcot, M.: Sur un cas de paraplégie diabétique, Arch. de Neurol. 19:318 (May) 1890 . 
neuralgia. Rimbaud's case, ${ }^{10}$ on the other hand, was sensory only, showing disturbance of all forms of sensation. The cases of Packard, ${ }^{11}$ Pryce, ${ }^{12}$ Unschuld ${ }^{13}$ and Findlay ${ }^{3}$ were complicated so as to make conclusions uncertain. Buzzard's ${ }^{5}$ case was the only one of typical sensorimotor neuritis. Williamson, ${ }^{14}$ who has seen many cases of diabetes, states that sensorimotor neuritis is either very rare or that it does not exist at all. My own conclusions are that cases showing with parallel intensity, and in the same nerve distribution, both paralysis and atrophy and changes in deep and superficial sensation do not occur as a result of diabetes. In other words, true sensorimotor neuritis does not occur.

However, there seem to be two groups of cases which, at first sight, simulate polyneuritis: one due to disease of the anterior horn cells or the intramedullary portion of the lower motor neurons and associated with neuralgia, the other due to involvement of the intramedullary sensory tract, as in some forms of tabes. The following case from the service of Dr. Foster Kennedy at Bellevue Hospital is an example of the combination of these.

\section{CASE REPORT}

The chief complaint of Mrs. A. L., admitted to Bellevue Hospital Oct. 2, 1920, was inability to walk. Her family and past histories were negative; alcohol had not been used and there was no syphilis. Two weeks ago the patient was unable to walk on account of pain and stiffness about the ankles. There was no swelling of the joints.

Physical Examination.-The patient did not look ill. The general medical examination was negative. The pupils reacted fairly well to light and in accommodation. The deep reflexes were normal in the upper extremities, absent in the lower. There was no Babinski sign and no ankle clonus. No sensory disorders were noted. On October 5, the patient could not walk as her legs doubled up under her. On the right there was paralysis of the iliopsoas and tibialis anticus. There was complete paralysis of the quadriceps. The patient was

10. Rimbaud, L.: Névrite diabétique, Gaz. d. hôp. 82:1555 (Nov. 2) 1909; abstr., Rev. Neurol. 20:502, 1910; abstr., Neurol. Centralbl. 1910, p. 936.

11. Packard, F. H.: A Case of Neuritis in the Course of Diabetes, Boston M. J., 1902, p. 324.

12. Pryce, T. D.: A Case of Perforated Ulcers of Both Feet Associated with Diabetic and Ataxic Symptoms, Lancet 2:11 (July 2) 1887; 1888, p. 59. On Diabetic Neuritis with a Clinical and Pathological Description of Three Cases of Diabetic Pseudo-tabes, Brain 16:416, 1893; abstr., Rev. Neurol. 2:122. 1894.

13. Unschuld: Ueber ein bisher nicht gewürdigtes Symptom des Diabetes Mellitus, Berl. klin. Wchnschr. 28:649, 1894.

14. Williamson, R. T.: Diabetes and Its Treatment, Edinburgh, 1898; The Nervous Complications of Diabetes Which Are Associated With Changes in the Peripheral Nerves and Spinal Cord, Rev. de méd. 31:872, 1911; abstr., Rev. Neurol. 24:304, 1912; Diseases of the Spinal Cord, London, 1911. 
unable to hold up her legs. Knee and Achilles reflexes were absent. The arms were normal. On October 8, the upper extremities were normal. The abdominal reflexes were absent (lax abdominal wall). She complained of pains in the legs. The blood Wassermann reaction was negative. On October 15, urinalysis revealed sugar, 4 per cent., $36.4 \mathrm{gm}$. On October 18, there were 256 mg. of blood sugar. On November 2, patchy analgesia and tactile anesthesia were present over the feet and legs, which was neither clearly neural nor segmental in distribution. Position sense in the great toes was normal. On November 28, electric tests of muscles were made. Condenser current (normal response, 0.01 to 0.05 microfarads) :

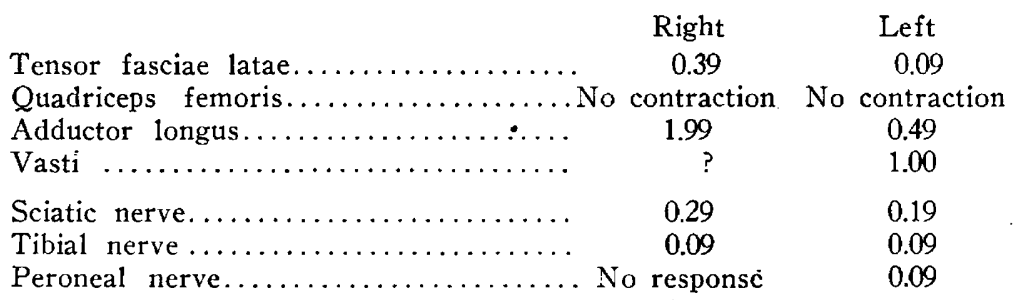

On January 6 sensory changes were less and of no definite distribution. Muscle sense was normal in the toes. The patient was discharged, unimproved. On June 1 the patient was visited at her home. She had been in bed and had not walked since leaving the hospital. She had been on an ordinary diet. Her cutaneous and muscle sensations were normal. The legs were flexed at the hip and knee. There was contracture of the hamstrings. Flexion of the thigh by the iliopsoas was poorly executed. No extension at the knee was possible. There was marked atrophy of the quadriceps femoris. Movements of the toes and at the ankle were present. The knee and Achilles jerks were absent. There was no Babinski sign. In brief, motor paralysis with atrophy of the quadriceps and weakness of the muscles supplied by the femoral and external popliteal nerves, was present.

Impression.-The condition appeared to be chronic anterior poliomyelitis. The neuralgic pains and sensory changes, irregular at first and absent at the last examination, suggested a transient intramedullary sensory radiculitis.

(b) Mononeuritis.-There are also reports of isolated paralysis (mononeuritis), though these are not numerous. The sciatic cases were, with one exception, all reported in pre-Wassermann days and on that score alone are not entirely trustworthy. The most important group of paralyses are those of the muscles supplied by the crural and obturator nerves. In 1913, Byrnes ${ }^{15}$ could find only ten or eleven cases of "crural neuritis." A number of these are reported as "polyneuritis." In the case reports which I have found there have been recorded no objective sensory changes, only neuralgic pains were present. Bruns, ${ }^{16}$ reviewing the matter in 1907 , stated that the obturator and

15. Byrnes, Charles Metcalfe: Anterior Crural Neuritis, J. Nerv. \& Ment. Dis. 40:758-778, 1913; 41:19-31, 1914.

16. Bruns, L.: Ueber Neuritis Diabetica und Alcoholica, Deutsch. Ztschr. f. Nervenheilk. 36:17, 1908; abstr., Neurol. Centralbl. 27:1000, 1908. 
crural nerves were especially involved in diabetes. But with objective sensory changes lacking, involvement of the peripheral parts of the neurons cannot be assumed.

(c) Motor Type.-The cases belong rather in the motor group noted in the foregoing than in a group of peripheral neuritides. The motor cases not of "mononeuritic" distribution described as "polyneuritis" also showed a predominance of involvement of the muscles supplied by the crural nerves, as illustrated in the foregoing case report. This leads to the belief that the cases called obturator and crural neuritis are mild forms of a more widely spread paralysis of the legs, incorrectly called "polyneuritis." .The earliest manifestation of this condition is "giving way of the legs" owing to slight weakness of the flexors of the thigh and the extensors of the knee. When this becomes aggravated the picture resembles that of neuritis. Indeed, a proximal form of paralysis of the lower extremities does not seem to be an uncommon manifestation of diabetes mellitus and presents the clinical picture of spinal cord involvement and chronic anterior poliomyelitis rather than of polyneuritis. Such proximal involvement resembling polyneuritis results from other causes and is of central origin.

(d) Sensory Type.--Sensory disorders of diabetes may be divided into a number of types, each of which represents a greater involvement than its predecessors: first, increased reflexes, then diminished or absent reflexes due to involvement of the afferent part of the arc. A further stage consists of diminution or absence of the sensation of touch. Pain and the temperature are rarely affected. Finally, - deep sensation may be involved, producing pseudotabes. To any of these neuralgia may be added.

The cases of pseudotabes prior to 1906, the beginning of the Wassermann era, are better discarded since there is always some doubt as to the presence of an old undetected syphilitic infection. Subsequent to that date very little is to be found. Van Noorden, ${ }^{17}$ in 1910 , said that he had seen only three cases which could be designated pseudotabes. One was alcoholic. He grouped these cases under the general heading of polyneuritis. Hartmann and Schrottenbach, ${ }^{18}$ in 1912, make no reference to cases subsequent to 1906 . They sum up by saying, "The question whether this form of disease be a true peripheral condition is more than doubtful in view of the investigations of Schweiger."

The problem is not an easy one to solve at the present time. That such a condition could arise from intramedullary root degeneration is

17. Van Noorden, Carl: Die Zuckerkrankheit und Ihre Behandlung, Berlin, 1910.

18. Hartmann, Fritz, and Schrottenbach, Heinz: Die Endogen Vergiftungen des Nervensystems, in Lewandowsky: Handbuch der Neurol. 3:1106, 1912. 
obvious. Whether it really does remains to be decided. Cases which would come under this heading must be, at least, quite free of any evidence of syphilis. The cases described showed a strictly sensory syndrome. They therefore correspond to the notion that the lesion is located in the intramedullary sensory root, whether syphilitic or diabetic or both.

(e) Cranial Palsies. - With the exception of paralysis of the third, fourth, sixth and seventh cranial nerves, paralyses of the cranial nerves are rare, many of them complicated in such a way as to be open to doubt. Such cases as do occur are uncommon. Paralysis of the eye-muscles is of the peripheral type. Paralysis of the facial nerve, of which I have seen three examples, is also peripheral in type. This agrees with the notion of peripheral neuron involvement.

\section{STATISTICS OF PERSONAL RESEARCH}

The frequency of involvement of the intramedullary sensory root may be judged by the fact that of about 450 case records examined at the Vanderbilt Clinic 40 per cent. showed abnormal knee reflexes (Fig. 1). Many of these had associated neuralgias or paresthesias. This corresponds to the findings of other observers. The abnormal reflexes are, in the vast majority of cases, either the knee or Achilles reflexes. The lumbosacral segments are usually those affected. This corresponds with Bruns' idea that diabetes mellitus usually affects the muscles supplied by the obturator and crural nerves, and with the distribution of the motor forms of paralysis already described. The upper extremities are relatively immune, though atrophies and reflex changes are occasionally found. In contrast to 40 per cent. of nearly 450 cases with abnormal knee jerks, I have found only one case showing muscular atrophy. It would therefore seem that diabetes mellitus commonly produces a strictly sensory disorder, and rarely a motor disorder.

EXPLANATION OF THE SITE OF INVOLVEMENT

What is the reason for the intramedullary involvement which the clinical pictures suggest? The neurilemma sheath stops at the pia. A lesion of the non-neurilemmatized portion of the peripheral neurons within the spinal cord will amply account for the clinical pictures. Such a selective action occurs under certain circumstances in other diseases such as diphtheria, tetanus and syphilis.

\section{CONCLUSIONS}

For the present we must rely on the clinical picture. Analysis of the records of others and my own experience in the clinic indicate involvement of the motor cells and roots or of the intramedullary por- 
tions of the sensory roots and their continuance within the spinal cord. Its analogues, the midbrain, pons and medulla, may be similarly affected. Both motor and sensory involvement may occur at the same time. Satisfactory clinical evidence of primary extramedullary involvement of the peripheral neurons, that is, peripheral neuritis, has not been obtained, either from a review of the clinical and pathologic reports in the literature or from my own experience.

\section{Decades}

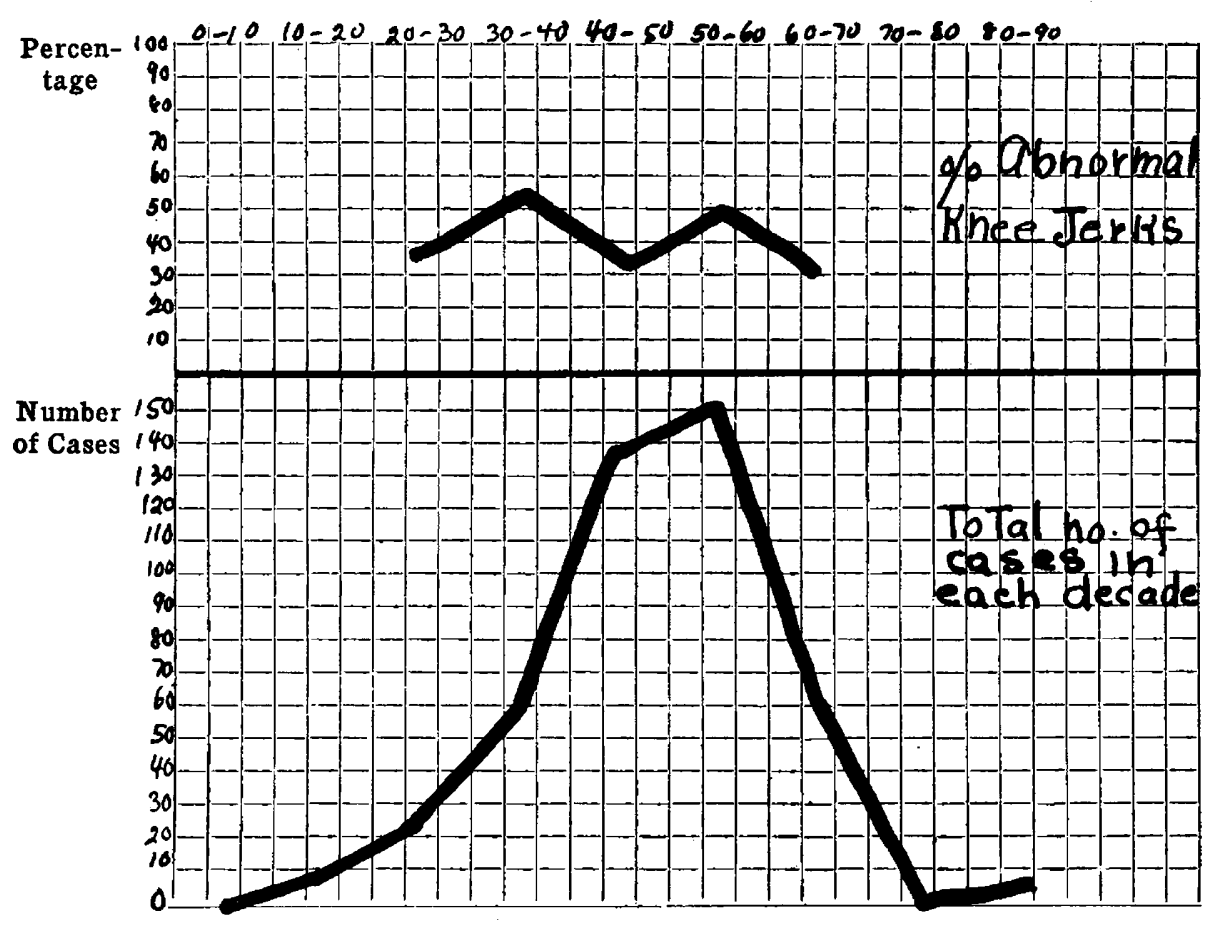

Results of testing knee jerks in cases of diabetes mellitus.

DISCUSSION

Dr. Hugr T. Patrick, of Chicago, called attention to these facts: First, in systemic poisoning affecting the peripheral nerves, it is well known that ordinarily the motor neuron is much more vulnerable than the sensory; second, diabetic patents are especially susceptible to general infections, the ordinary everyday infections. Dr. Patrick believed that in many of the cases in which the patients had painful legs the pain was not due to diabetes but to some infection. In other words, the pains belonged in the broad category of rheumatism.

Dr. Walter M. Kraus, of New York, in answer to Dr. Patrick, regarding the occurrence of pain, said that the time was so short it was impossible to 
go into detail, but he felt that one should be cautious in certain directions which Dr. Patrick had suggested, and also in other directions, namely, in the assumption that the pain was always peripherally produced. He said that it had been abundantly shown that pain might be centrally produced, and if it could be shown in the future that there was an involvement of the intramedullary portion of the root in diabetes, there was no reason why the pains and paresthesias could not be shown to be due to this involvement of the intramedullary portion of the root. The fact that these pains came and went with treatment indicated that that hypothesis might hold in the future.

141 West Seventy-Fifth Street. 